\title{
Surgical ablation of atrial fibrillation in patients with heart failure
}

Ali J. Khiabani, MD, Richard B. Schuessler, PhD, and Ralph J. Damiano, Jr, MD

With the aging of the population, the incidence of both atrial fibrillation (AF) and heart failure (HF) continues to increase, with a spiraling cost to health care services globally. ${ }^{2,3} \mathrm{AF}$ and $\mathrm{HF}$ often coexist, promoting a vicious cycle that leads to worsening and often rapid deterioration in a patient's condition. AF is both a cause and consequence of HF, with complex interactions that can lead to impairment of systolic and diastolic function not present in sinus rhythm. ${ }^{3}$ $\mathrm{AF}$ is also associated with a 3 -fold increased risk of HF. The EuroHeart Failure Survey reported that $25 \%$ of HF patients with reduced ejection fraction (left ventricular ejection fraction $[\mathrm{LVEF}]<40 \%$ ) had chronic $\mathrm{AF}^{4}$, with many likely having a component of tachycardia-induced cardiomyopathy (TIC).

With the restoration of sinus rhythm and improved heart rate control, left ventricle (LV) function can be expected to normalize in patients with TIC. However, even in the absence of a rapid ventricular rate in $\mathrm{AF}$, an irregular ventricular rhythm has also been shown to lead to a reduction in LV function. ${ }^{5-8}$ Conversely, the neurohormonal and structural changes, including atrial and ventricular fibrosis observed in patients with $\mathrm{HF}$, create a proarrhythmic environment that favors the initiation and maintenance of AF. ${ }^{9}$ Canine studies by our group and others have shown that left atrial dilation leads to a significant shortening of the atrial effective refractory period, and slower and more inhomogeneous conduction. ${ }^{10,11}$ These changes have been implicated in the initiation of $\mathrm{AF}$ in humans and an increased AF inducibility in canine models of mitral regurgitation. ${ }^{10,12}$

From the Division of Cardiothoracic Surgery, Department of Surgery, Washington University School of Medicine, Barnes-Jewish Hospital, St Louis, Mo.

Supported by the National Institutes of Health (grant No. R01-HL032257 to Dr Damiano and Dr Schuessler and grant No. T32-HL007776 to Dr Damiano and Dr Khiabani) and the Barnes-Jewish foundation.

Received for publication March 26, 2020; revisions received May 22, 2020; accepted for publication May 26, 2020; available ahead of print Aug 15, 2020.

Address for reprints: Ralph J. Damiano, Jr, MD, Division of Cardiothoracic Surgery, Department of Surgery, Washington University School of Medicine, Barnes-Jewish Hospital, Campus Box 8234, 660 S Euclid Ave, St Louis, MO 63110 (E-mail: damianor@wustl.edu).

J Thorac Cardiovasc Surg 2021;162:1100-5

$0022-5223 / \$ 36.00$

Copyright $(\odot 2020$ by The American Association for Thoracic Surgery

https://doi.org/10.1016/j.jtcvs.2020.05.125

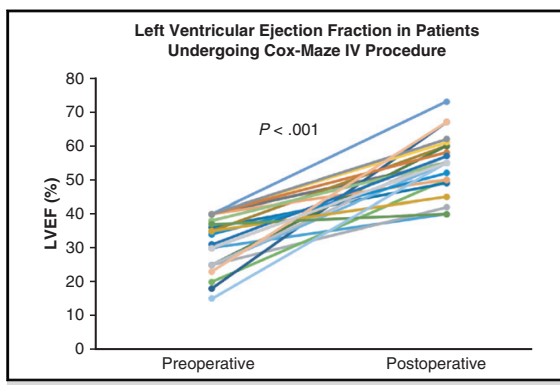

Improvement in left ventricular function following stand-alone CMP IV. Reproduced with permission.

CENTRAL MESSAGE

Surgical ablation of AF can

restore sinus rhythm in selected

patients with reduced ejection

fraction and is associated with

significant improvement in left

ventricular function and

symptomatic relief.

This Invited Expert Opinion provides a perspective on the following paper: N Engl J Med. 2018 Feb 1;378(5):417-427. NEJMoa1707855.

See Commentaries on pages 1106 and 1107.

\section{MEDICAL THERAPY AND CATHETER-BASED ABLATION}

Regardless of which comes first, patients with concomitant AF and HF have a significantly worse prognosis. ${ }^{3,6}$ The goals of therapy are similar to other patients with AF: to prevent stroke, control the ventricular rate and rhythm, reduce symptoms, and improve functional status and quality of life. Unfortunately, pharmacologic rate and rhythm control strategies, which come with serious side effects, have not led to improvements in LV function, quality of life, or cardiovascular death. .,13 $^{9}$

In contradistinction, multiple studies have shown catheter ablation to be superior to medical therapy with improved quality of life, exercise capacity, LV function, 
and reduced AF burden., ${ }^{2,-17}$ In 2018, Marrouche and colleagues ${ }^{16}$ reported a randomized controlled trial (Catheter Ablation for Atrial Fibrillation with Heart Failure) comparing patients with $\mathrm{AF}$ and $\mathrm{HF}$ who underwent catheter-based ablation $(\mathrm{n}=179)$ to those with medical therapy alone (rate or rhythm control) $(\mathrm{n}=184)$. Catheter-based ablation for AF in this patient population was associated with a significantly lower mortality rate from any cause or hospitalization for worsening HF. Catheter ablation was associated with significant improvement in LV function, exercise capacity, and a reduction in $\mathrm{AF}$ burden. ${ }^{16}$ Patients with an ejection fraction $\leq 35 \%$ were enrolled. In the ablation group, $63.1 \%$ of patients in comparison to $21.7 \%$ in the medical therapy group $(P<.001)$ were in sinus rhythm at the 60 -month follow-up visit. The adjudicated rate of recurrence of $\mathrm{AF}$ in the ablation group among those who had actually undergone ablation and who were followed for up to 60 months was $50.0 \%$ (75 of 151 patients), with an average of $1.3 \pm 0.5$ ablation procedures per treated patient. ${ }^{16}$

In agreement with this randomized study, a subgroup analysis of patients with HF from the largest randomized controlled trial to date, Catheter Ablation Versus Antiarrhythmic Drug Therapy, was recently analyzed in a systemic review and showed that catheter ablation was associated with all-cause mortality benefit, improvement in ventricle function, and reduction in cardiovascular hospitalization and AF recurrence. ${ }^{18,19}$

Lifelong maintenance of rate and rhythm control is crucial in these patients as recurrence of the arrhythmia is associated with the rapid development of symptomatic HF and worsening of left ventricular systolic function. ${ }^{1}$ For this reason, for patients who develop $\mathrm{HF}$ as a result of AF, both the 2013 American College of Cardiology Foundation/American Heart Association guideline for the management of heart failure and the 2019 American College of Cardiology/American Heart Association/Heart Rhythm Society guideline for the management of patients with AF, recommend nonsurgical rhythm control strategies. $^{20,21}$

Despite improvements in technology and techniques, catheter-based ablation outcomes remain relatively poor, particularly in patients with chronic AF. In a study of 255 patients who underwent catheter ablation, of whom $43 \%$ had paroxysmal AF, the AF-free survival after a single ablation procedure was $32 \%$ for the overall cohort at 10 years (39\% for paroxysmal vs $24 \%$ for nonparoxysmal AF $[P=.001])$. Allowing for multiple catheter ablations in those with failure improved the AF-free survival to $52 \%$ at 10 years $(61 \%$ paroxysmal vs $44 \%$ nonparoxysmal $[P=.002]) .{ }^{22}$ Several other studies have reported earlyand midterm success rates after catheter ablations with equally disappointing results. ${ }^{23,24}$

\section{SURGICAL ABLATION}

Owing to these disappointing results of catheter ablation, surgical ablation is generally the only treatment alternative to atrioventricular nodal ablation with permanent pacemaker implantation in symptomatic patients who are refractory to medical and catheter ablation therapy. ${ }^{25}$ The most effective surgical technique for the management of $\mathrm{AF}$ has been the Cox maze procedure (CMP), introduced by James Cox and colleagues in 1987. The cut-and-sew version-CMP III-became the gold standard because long-term follow-up had $>90 \%$ freedom from symptomatic $\mathrm{AF}^{26}$ In this procedure, surgical incisions were made in both atria to create lines of conduction block to prevent AF. However, due to its technical complexity, few surgeons adopted the procedure. In 2002, a modified version, CMP IV, was introduced by our group utilizing bipolar radiofrequency and cryoablation devices to replace most of the atrial incisions. ${ }^{27} \mathrm{CMP}$ IV is as effective as its predecessor at restoring sinus rhythm while also reducing operative morbidity and mortality. ${ }^{28-30}$ It is the only surgical operation to receive Food and Drug Administration indication for the treatment of AF. Additionally, in contradistinction to catheter ablation and more limited surgical lesion sets, CMP was found to be equally effective in patients with both paroxysmal and nonparoxysmal AF. ${ }^{29,30}$

The Society of Thoracic Surgeons, The Heart Rhythm Society, European Heart Rhythm Association, and the European Cardiac Arrhythmia Society have recommended surgical ablation as a primary standalone procedure to restore sinus rhythm for patients who are refractory to class I or III antiarrhythmic drugs and/or catheter-based therapy (Class IIa, Level B, nonrandomized). ${ }^{31,32}$ Nonetheless, there is currently no consensus regarding the referral for surgical ablation of patients diagnosed with $\mathrm{HF}$ and $\mathrm{AF}$. This is due to the paucity of clinical series and randomized trials in patients with HF undergoing surgical ablation. However, it can be assumed that with the higher efficacy of CMP, and its documented low morbidity and mortality, the results of the large catheter ablation trials summarized above would be applicable to the surgical ablation population, and can be used to justify a more aggressive surgical approach.

Several retrospective case series have shown improvement in LVEF after the restoration of sinus rhythm with surgical ablation in the general population of patients with AF. These studies had limited data regarding patients with severely depressed ejection and AF without structural or coronary heart disease. ${ }^{33-36}$ More recently, our group reported a series of patients with severely depressed LVEF $\leq 40 \%$ who underwent standalone CMP IV. In this patient cohort, $85 \%$ of patients ( 29 out of 34 ) had clinical (New York Heart Association [NYHA] functional class II 
or higher) HF symptoms. Restoration of sinus rhythm with CMP IV was associated with significant improvement in LVEF $(32 \% \pm 8 \%$ to $55 \% \pm 8 \% ; P<.001$ ) (Figure 1 , $A$ ). Additionally, patients' NYHA functional classification improved significantly from baseline to final follow-up $(2.3 \pm 0.8$ to $1.3 \pm 0.6 ; P=.02)$. At last follow-up, $91 \%$ of patients had NYHA class I or II symptoms $(P<.001)$ (Figure $1, B) .{ }^{1}$ The complications associated with surgical ablation in this patient population remained relatively low, as reported by our group and others. ${ }^{1,33-36}$

In another similar study by Pozzoli and collegues, ${ }^{36} 39$ highly symptomatic patients with reduced ejection fraction underwent standalone surgical ablation. At a mean followup of $29.4 \pm 14.2$ months, freedom from arrhythmias on or off antiarrhythmic drugs was $92 \%$ and $93 \%$ at 24 and 36 months, respectively. Ejection fraction normalized in all cases, from $51.3 \% \pm 9 \%$ to $61.1 \% \pm 3 \%(P<.001)$ overall, and from $37.0 \% \pm 10 \%$ to $60.3 \% \pm 3 \%$ $(P<.001)$ when LEVF was $\leq 45 \%$ preoperatively. ${ }^{36}$

\section{PATIENT SELECTION}

Patient selection can be challenging (Figure 2). Identifying a suitable patient who can benefit from surgical ablation is extremely important in this cohort of patients. It is important to distinguish patients with reversible HF secondary to $\mathrm{AF}$ with or without concomitant structural or coronary heart disease (eg, tachycardia-induced cardiomyopathy), from those experiencing cardiomyopathies or other nonreversible forms of HF. At our center, all patients undergo an evaluation with echocardiography. Gadolinium- enhanced cardiac magnetic resonance imaging (MRI) is also performed to assess for other causes of cardiomyopathy, myocardial viability, and fibrosis. If there is any abnormality on cardiac MRI or a high index of suspicion, endomyocardial biopsies are performed. ${ }^{1}$ As discussed previously, sustained tachycardia may result in both atrial and ventricular fibrosis, which can influence the degree of ventricular function improvement. ${ }^{2,3,17}$ Recently, the Catheter Ablation versus Medical Rate Control in Atrial Fibrillation and Systolic Dysfunction MRI study randomized patients with persistent $\mathrm{AF}$ and idiopathic cardiomyopathy (LVEF $\leq 45 \%$ ) to medical treatment or catheter ablation. Randomization was done following cardiac MRI to assess the degree of LV fibrosis by late gadolinium enhancement. Compared with the medical group, the catheter ablation group had superior rhythm control and LV function improvement. However, the degree of ventricular fibrosis predicted the extent of LVEF recovery. On multivariate analysis, only the absence of late gadolinium enhancement was found to predict LVEF normalization. ${ }^{17}$ Thus, preoperative cardiac MRI should be strongly considered in all patients with a tentative diagnosis of TIC to help gauge the degree of improvement from a patient may gain from surgical ablation.

Additionally, patients with dilated cardiomyopathy should be identified. Patients with idiopathic dilated cardiomyopathy tend to have larger LV end-diastolic diameters than patients with TIC. Jeong and colleagues ${ }^{37}$ reported that $\mathrm{LVEF} \leq 45 \%$ and LV end-diastolic dimension $\leq 61 \mathrm{~mm}$ is predictive of TIC with a sensitivity of $100 \%$ and a specificity of $71 \%$. Furthermore, in patients with

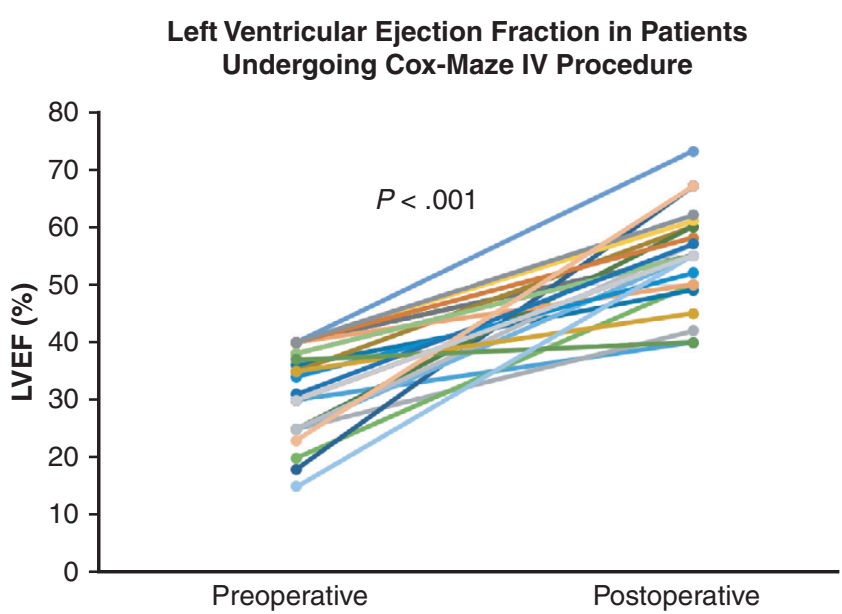

A

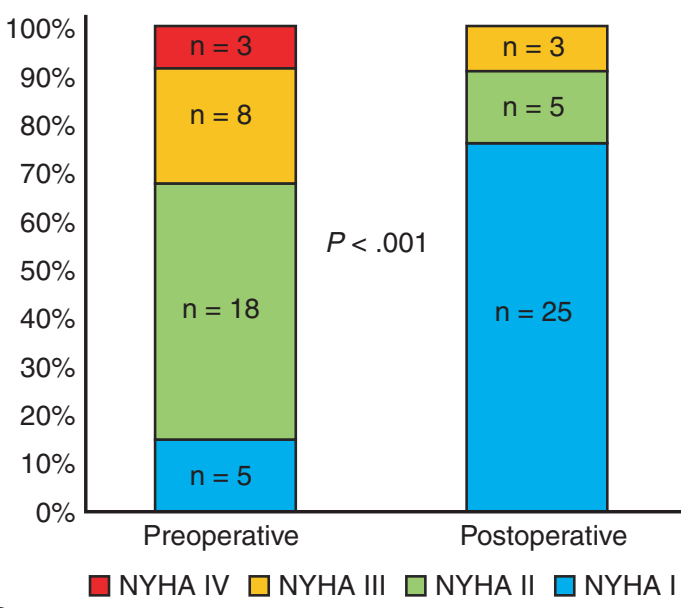

B

FIGURE 1. Improvement in left ventricle (LV) function (A) in patients with a left ventricular ejection fraction $(L V E F) \leq 40 \%$ or less at a median follow-up of 22 months after the standalone Cox-maze IV procedure. Left ventricular function improved from $32 \% \pm 8 \%$ to $55 \% \pm 8 \%$ (95\% confidence interval, 0.51-0.58; $P<.001)$. Improvement in New York Heart Association (NYHA) functional class (B) following the stand-alone Cox-maze IV procedure. At late follow-up, 30 of 33 patients $(91 \%)$ had NYHA functional class I or II symptoms $(P<.001)$. Reproduced with permission. ${ }^{1}$ 


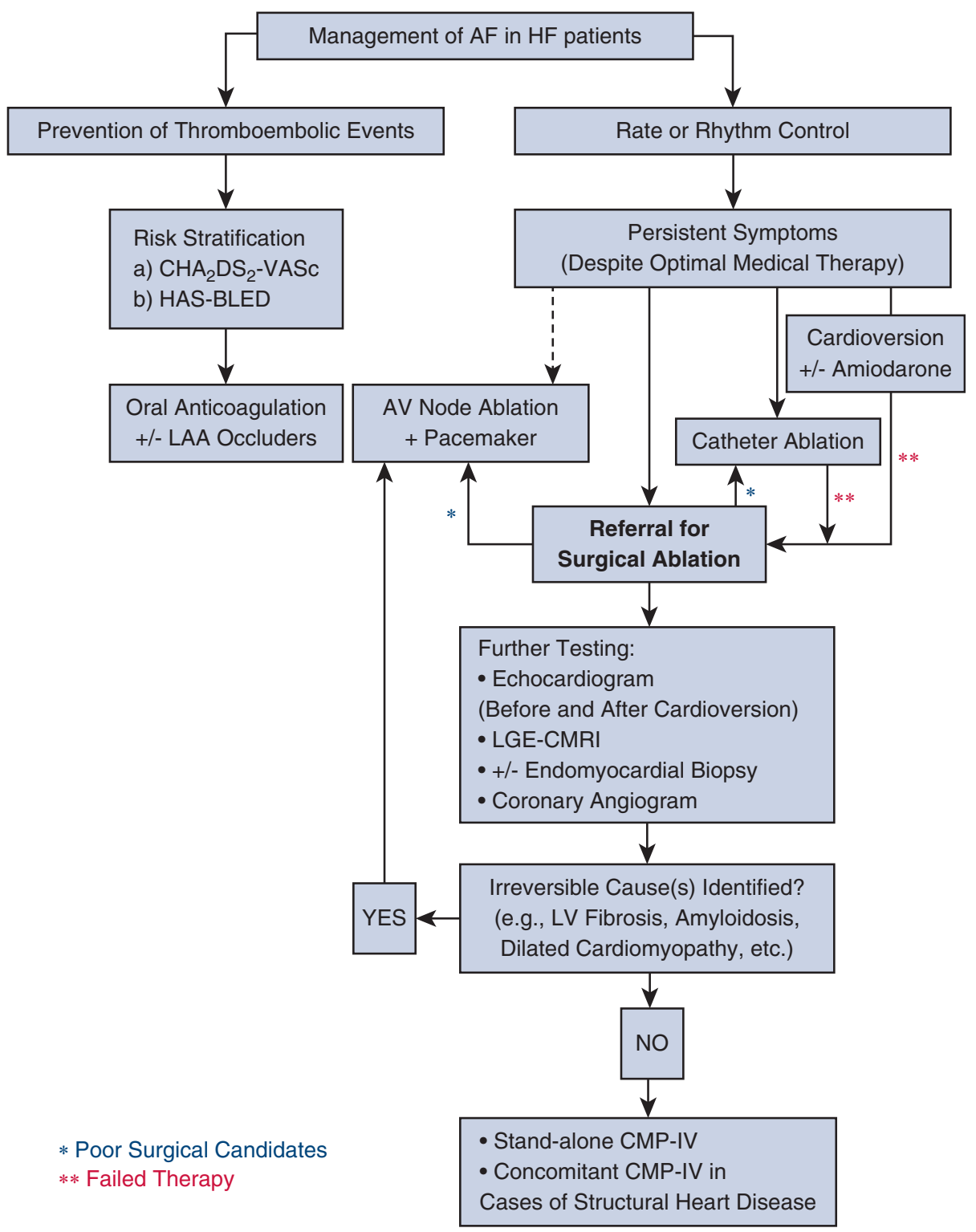

FIGURE 2. Management of patients with atrial fibrillation $(A F)$ and heart failure $(H F)$ at our institution. $\mathrm{CHA}_{2} D S_{2}-V A S c, \mathrm{CHF}$ or $\mathrm{LVF} \leq 40 \%$, Hypertension, Age $\geq 75$, Diabetes, Stroke/TIA/Thromboembolism, Vascular Disease, Age 65 - 74, Female; HAS-BLED, Hypertension, Abnormal Liver or Renal Function, Stroke, Bleeding, Labile INR, Elderly (Age > 65), Drug or Alcohol; $L A A$, left atrial appendage; AV node, atrioventricular node; $L G E-C M R I$, late gadolinium enhancement cardiac magnetic resonance imaging; CMP-IV, Cox-maze IV procedure.

LVEF $<30 \%$, LV diastolic dimension $\leq 66 \mathrm{~mm}$ is predictive of TIC with a sensitivity of $100 \%$ and a specificity of $83 \% .{ }^{37}$ Lastly, when in doubt, medical management should be initiated, and cardioversion should be considered. If LVEF improved shortly after the restoration of sinus rhythm and when the rate is more adequately controlled, the diagnosis of TIC is more likely, and the patient is much more likely to benefit from surgical ablation. ${ }^{5,34}$ Patients with irreversible causes of HF (eg, LV fibrosis, amyloidosis, and ischemic and/or dilated cardiomyopathy) should not be offered standalone surgical ablation. Despite the restoration of sinus rhythm, LV function often will not recover in these patients.

\section{CONCLUSIONS}

Given the exceptional outcomes of CMP, it should always be considered as an option in treating patients with $\mathrm{AF}$ and HF. When performed correctly, in selected patients with HF, it provides reversal of AF-related cardiomyopathy with excellent outcomes, symptomatic relief, and negligible 
risk. Additionally, CMP IV is a better alternative to atrioventricular nodal ablation with permanent pacemaker implantation. The latter, although effective in controlling the ventricular rate, does not improve LVEF and exercise capacity as effectively as treatments that restore sinus rhythm. ${ }^{25}$ Considering the excellent late outcomes of CMP, with more than $80 \%$ of patients free from recurrent $\mathrm{AF}$ at 5 years, ${ }^{38,39}$ the positive results from the catheter ablation versus medical management trials in the HF population, such as Catheter Ablation for Atrial Fibrillation with Heart Failure, should be translatable to the surgical population. Moreover, given the other potential long-term benefits of CMP IV, including increased overall survival and stroke reduction, concomitant surgical ablation should be considered in this surgically high-risk population, despite the longer operative time. . $^{1,30,39}$

Although there have been only a few retrospective studies reporting the outcomes of surgical ablation for $\mathrm{AF}$ in patients with HF, it is our opinion that future guideline committees need to consider the addition of CMP IV to their recommendations for the management of patients with $\mathrm{AF}$ and HF who are undergoing cardiac surgery for another reason-or as a standalone operation in carefully selected patients. Although we need to create a better evidence base for surgical ablation in this population through the performance of prospective, multicenter clinical trials, there are ample published data establishing the important role of ablation in patients with AF and HF. Surgeons need to be aware that HF and the presence of TIC is a strong indication for proceeding with $\mathrm{AF}$ ablation in properly selected patients.

\section{Conflict of Interest Statement}

Dr Damiano has worked as a speaker and received research funding from AtriCure; as a consultant for Medtronic; and as a speaker for LivaNova, Inc, and Edwards Lifesciences. All other authors reported no conflicts of interest.

The Journal policy requires editors and reviewers to disclose conflicts of interest and to decline handling or reviewing manuscripts for which they may have a conflict of interest. The editors and reviewers of this article have no conflicts of interest.

\section{References}

1. Khiabani AJ, Adademir T, Schill MR, Sinn LA, Schuessler RB, Moon MR, et al Surgical ablation of atrial fibrillation in patients with tachycardia-induced cardiomyopathy. Ann Thorac Surg. 2019;108:443-50.

2. Turagam MK, Garg J, Whang W, Sartori S, Koruth JS, Miller MA, et al. Catheter ablation of atrial fibrillation in patients with heart failure: a meta-analysis of randomized controlled trials. Ann Intern Med. 2019;170:41-50.

3. Kotecha D, Piccini JP. Atrial fibrillation in heart failure: what should we do? Eur Heart J. 2015;36:3250-7.

4. Lenzen MJ, Scholte op Reimer WJM, Boersma E, Vantrimpont PJMJ, Follath F, Swedberg K, et al. Differences between patients with a preserved and a depressed left ventricular function: a report from the EuroHeart failure survey. Eur Heart J. 2004;25:1214-20.
5. Gopinathannair R, Etheridge SP, Marchlinski FE, Spinale FG, Lakkireddy D, Olshansky B. Arrhythmia-induced cardiomyopathies: mechanisms, recognition, and management. J Am Coll Cardiol. 2015;66:1714-28.

6. Hagens VE, Van veldhuisen DJ, Kamp O, Rienstra M, Bosker HA, Veeger NJ, et al. Effect of rate and rhythm control on left ventricular function and cardiac dimensions in patients with persistent atrial fibrillation: results from the RAte Control versus Electrical Cardioversion for Persistent Atrial Fibrillation (RACE) study. Heart Rhythm. 2005;2:19-24.

7. Damiano RJ, Tripp HF, Asano T, Small KW, Jones RH, Lowe JE. Left ventricular dysfunction and dilatation resulting from chronic supraventricular tachycardia. J Thorac Cardiovasc Surg. 1987;94:135-43.

8. Daoud EG, Weiss R, Bahu M, Knight BP, Bogun F, Goyal R, et al. Effect of an irregular ventricular rhythm on cardiac output. Am J Cardiol. 1996;78:1433-6.

9. Carlisle MA, Fudim M, Devore AD, Piccini JP. Heart failure and atrial fibrillation, like fire and fury. JACC Heart Fail. 2019;7:447-56.

10. Ruaengsri C, Schill MR, Khiabani AJ, Khiabani AJ, Manghelli JL, Carter DI, et al. The hemodynamic and atrial electrophysiologic consequences of chronic left atrial volume overload in a controllable canine model. J Thorac Cardiovasc Surg. 2018;156:1871-9.e1.

11. Solti F, Vecsey T, Kékesi V, Juhász-nagy A. The effect of atrial dilatation on the genesis of atrial arrhythmias. Cardiovasc Res. 1989;23:882-6.

12. Buxton AE, Waxman HL, Marchlinski FE, Josephson ME. Atrial conduction: effects of extra stimuli with and without atrial dysrhythmias. Am J Cardiol. 1984;54:755-61.

13. Roy D, Talajic M, Nattel S, Wyse DG, Dorian P, Lee KL, et al. Rhythm control versus rate control for atrial fibrillation and heart failure. N Engl J Med. 2008; 358:2667-77.

14. Di Biase L, Mohanty P, Mohanty S, Santangeli P, Trivedi C, Lakkireddy D, et al. Ablation versus amiodarone for treatment of persistent atrial fibrillation in patients with congestive heart failure and an implanted device: results from the AATAC multicenter randomized trial. Circulation. 2016;133:1637-44.

15. Macdonald MR, Connelly DT, Hawkins NM, Steedman T, Payne J, Shaw M, et al. Radiofrequency ablation for persistent atrial fibrillation in patients with advanced heart failure and severe left ventricular systolic dysfunction: a randomised controlled trial. Heart. 2011;97:740-7.

16. Marrouche NF, Brachmann J, Andresen D, Siebels J, Boersma L, Jordaens L, et al. Catheter ablation for atrial fibrillation with heart failure. $N$ Engl J Med. 2018;378:417-27.

17. Prabhu S, Taylor AJ, Costello BT, Kaye DM, McLellan AJA, Voskoboinik A, et al. Catheter ablation versus medical rate control in atrial fibrillation and systolic dysfunction: the CAMERA-MRI study. J Am Coll Cardiol. 2017;70: 1949-61.

18. Packer DL, Mark DB, Robb RA, Monahan KH, Bahnson TD, Poole JE, et al. Effect of catheter ablation vs antiarrhythmic drug therapy on mortality, stroke, bleeding, and cardiac arrest among patients with atrial fibrillation: the CABANA randomized clinical trial. JAMA. 2019;321:1261-74.

19. Asad ZUA, Yousif A, Khan MS, Al-khatib SM, Stavrakis S. Catheter ablation versus medical therapy for atrial fibrillation. Circ Arrhythm Electrophysiol. 2019;12:e007414.

20. Yancy CW, Jessup M, Bozkurt B, Butler J, Casey DE Jr, Drazner MH, et al. 2013 $\mathrm{ACCF} / \mathrm{AHA}$ guideline for the management of heart failure: a report of the American College of Cardiology Foundation/American Heart Association task force on practice guidelines. J Am Coll Cardiol. 2013;62:e147-239.

21. January CT, Wann LS, Calkins H, Chen LY, Cigarroa JE, Cleveland JC Jr, et al. 2019 AHA/ACC/HRS focused update of the 2014 AHA/ACC/HRS guideline for the management of patients with atrial fibrillation. Circulation. 2019;140: e125-51.

22. Gaita F, Scaglione M, Battaglia A, Matta M, Gallo C, Galatà M, et al. Very longterm outcome following transcatheter ablation of atrial fibrillation. Are results maintained after 10 years of follow up? Europace. 2018;20:443-50.

23. Gökoğlan Y, Mohanty S, Güneş MF, Trivedi C, Santangeli P, Gianni C, et al. Pulmonary vein antrum isolation in patients with paroxysmal atrial fibrillation: more than a decade of follow-up. Circ Arrhythm Electrophysiol. 2016;9:e003660.

24. Ganesan AN, Shipp NJ, Brooks AG, Kuklik P, Lau DH, Lim HS, et al. Long-term outcomes of catheter ablation of atrial fibrillation: a systematic review and meta-analysis. J Am Heart Assoc. 2013;2:e004549.

25. Chatterjee NA, Upadhyay GA, Ellenbogen KA, Mcalister FA, Choudhry NK, Singh JP. Atrioventricular nodal ablation in atrial fibrillation: a meta-analysis and systematic review. Circ Arrhythm Electrophysiol. 2012;5:68-76.

26. Prasad SM, Maniar HS, Camillo CJ, Schuessler RB, Boineau JP, Sundt TM III, et al. The Cox maze III procedure for atrial fibrillation: long-term efficacy in 
patients undergoing lone versus concomitant procedures. J Thorac Cardiovasc Surg. 2003;126:1822-8.

27. Prasad SM, Maniar HS, Schuessler RB, Damiano RJ. Chronic transmural atrial ablation by using bipolar radiofrequency energy on the beating heart. $J$ Thorac Cardiovasc Surg. 2002;124:708-13.

28. Lall SC, Melby SJ, Voeller RK, Zierer A, Bailey MS, Guthrie TJ, et al. The effect of ablation technology on surgical outcomes after the Cox-maze procedure: a propensity analysis. J Thorac Cardiovasc Surg. 2007;133:389-96.

29. Ruaengsri C, Schill MR, Khiabani AJ, Schuessler RB, Melby SJ, Damiano RJ. The Cox-maze IV procedure in its second decade: still the gold standard? Eur J Cardiothorac Surg. 2018;53(Suppl 1):i19-25.

30. Weimar T, Schena S, Bailey MS, Maniar HS, Schuessler RB, Cox JL, et al. The Cox-maze procedure for lone atrial fibrillation: a single-center experience over 2 decades. Circ Arrhythm Electrophysiol. 2012;5:8-14.

31. Badhwar V, Rankin JS, Damiano RJ, Gillinov AM, Bakaeen FG, Edgerton JR, et al. The Society of Thoracic Surgeons 2017 clinical practice guidelines for the surgical treatment of atrial fibrillation. Ann Thorac Surg. 2017;103: 329-41.

32. Calkins H, Hindricks G, Cappato R, Kim YH, Saad EB, Aguinaga L, et al. 2017 HRS/EHRA/ECAS/APHRS/SOLAECE expert consensus statement on catheter and surgical ablation of atrial fibrillation. Heart Rhythm. 2017;14:e275-444.

33. Ad N, Henry L, Hunt S. The impact of surgical ablation in patients with low ejection fraction, heart failure, and atrial fibrillation. Eur J Cardiothorac Surg. 2011; 40:70-6.
34. Stulak JM, Dearani JA, Daly RC, Zehr KJ, Sundt TM, Schaff HV. Left ventricular dysfunction in atrial fibrillation: restoration of sinus rhythm by the Cox-maze procedure significantly improves systolic function and functional status. Ann Thorac Surg. 2006;82:494-500.

35. Pecha S, Ahmadzade T, Schäfer T, Subbotina I, Steven D, Willems S, et al. Safety and feasibility of concomitant surgical ablation of atrial fibrillation in patients with severely reduced left ventricular ejection fraction. Eur J Cardiothorac Surg. 2014;46:67-71.

36. Pozzoli A, Taramasso M, Coppola G, Kamami M, La Canna G, Della Bella P, et al. Maze surgery normalizes left ventricular function in patients with persistent lone atrial fibrillation. Eur J Cardiothorac Surg. 2014;46 871-6.

37. Jeong YH, Choi KJ, Song JM, Hwang ES, Park KM, Nam GB, et al. Diagnostic approach and treatment strategy in tachycardia-induced cardiomyopathy. Clin Cardiol. 2008;31:172-8.

38. Henn MC, Lancaster TS, Miller JR, Sinn LA, Schuessler RB, Moon MR, et al Late outcomes after the Cox maze IV procedure for atrial fibrillation. J Thorac Cardiovasc Surg. 2015;150:1168-76.

39. Henry L, Ad N. Performance of the Cox Maze procedure-a large surgical ablation center's experience. Ann Cardiothorac Surg. 2014;3:62-9.

Key Words: heart failure, atrial fibrillation, surgical ablation, Cox-maze IV procedure 